Article

\title{
Direct Formation of Sub-Micron and Nanoparticles of a Bioinspired Coordination Polymer Based on Copper with Adenine
}

\author{
Verónica G. Vegas ${ }^{1}$, Marta Villar-Alonso ${ }^{1}$, Carlos J. Gómez-García ${ }^{2}$ (D), Félix Zamora ${ }^{1,3,4, *}$ \\ and Pilar Amo-Ochoa 1,4,* \\ 1 Departamento de Química Inorgánica, Universidad Autónoma de Madrid, 28049 Madrid, Spain; \\ veronica.garciav@uam.es (V.G.V.); marta.villara@estudiante.uam.es (M.V.-A.) \\ 2 Departamento de Química Inorgánica, Instituto de Ciencia Molecular (ICMol), Parque Científico, \\ Universidad de Valencia, Catedrático José Beltrán, 2, Paterna, 46980 Valencia, Spain; \\ carlos.gomez@uv.es \\ 3 Instituto de Física de la Materia Condensada (IFIMAC), Universidad Autónoma de Madrid, \\ 28049 Madrid, Spain \\ 4 Institute for Advanced Research in Chemical Sciences (IAdChem), Universidad Autónoma de Madrid, \\ 28049 Madrid, Spain \\ * Correspondence: felix.zamora@uam.es (F.Z.); pilar.amo@uam.es (P.A.-O.); Tel.: +91-497-3200 (P.A.-O.)
}

Received: 6 October 2017; Accepted: 26 October 2017; Published: 1 November 2017

\begin{abstract}
We report on the use of different reaction conditions, e.g., temperature, time, and/or concentration of reactants, to gain control over the particle formation of a bioinspired coordination polymer based on copper(II) and adenine, allowing homogeneous particle production from microto submicro-, and up to nano-size. Additionally, studies on this reaction carried out in the presence of different surfactants gives rise to the control of the particle size due to the modulation of the electrostatic interactions. Stability of the water suspensions obtained within the time and $\mathrm{pH}$ has been evaluated. We have also studied that there is no significant effect of the size reduction in the magnetic properties of the $\mathrm{Cu}(\mathrm{II})$-adenine coordination polymer.
\end{abstract}

Keywords: coordination polymers; surfactants; nanoparticles

\section{Introduction}

Coordination Polymers (CPs) encompass a large group of compounds, formed by central metal ions and ligands linked by coordination bonds. Depending on the selected building blocks, CPs give rise to mono-, bi-, or three-dimensional structures. Additionally, one- or two-dimensional CPs can organize their three-dimensional networks using supramolecular interactions (such as hydrogen bonds) or van der Waals forces. The constituent building blocks of the CPs are also determinants in their physical and chemical properties [1-3]. Indeed, CPs are a fundamental source of multifunctional materials that may combine several physical properties, such as emission and magnetism, or emission and electrical conductivity [1]. Recently, a new family of CPs fusing bioinspired molecules, such as amino acids or peptides, and nucleobases as ligands has emerged. Although these bioinspired CPs could present new potential applications, the number of examples is still limited [4-12]. Indeed, nucleobases have intrinsic self-assembly abilities that can be used to direct the structure and function of CPs. This molecular self-assembly capability requires the establishment of intermolecular hydrogen bonds between complementary nucleobases or between nucleobases and others organic/inorganic ligands. Therefore, these new bioinspired CPs may show promising biological and/or biomedical interest [13]. Moreover, the production of these materials at the nanoscale will enhance their potential applications in biomedicine, e.g., traversing the cellular membrane [13]. 
Another important aspect in the nanomaterials area is that the physical properties may vary with respect to the bulk material as a consequence of this size reduction; therefore, methods for controlling the size distribution of nanomaterials are key prerequisites to gain access to a plethora of interesting physical properties and size-dependent phenomena inherent to nanomaterials.

In this regard, coordination polymers have, among other interesting advantages, the facility to be nanoprocessed [14-18]. In recent years, a large number of nanostructured coordination polymers have been obtained through different processes, such as interfacial reactions, hydro-solvothermal reactions, microemulsions, or using ultrasound [19] and the use of surfactants [20]. However, probably the simplest procedure based on fast precipitation controlling the concentration of the reactants or the addition of a poor solvent to the reaction medium, can also be enough to produce a reduction from the microscale to the nanoscale size, which it is little developed.

Finally, it is worth mentioning that, despite the number of studies focusing on the production of nanostructures of CPs with ligands of biological interest still being very limited, in most of the cases, the properties of these compounds have been studied at the bulk scale or even without an analysis of material size.

Therefore, the synthesis, size, morphology, and stability control of nanostructures based on coordination polymers bearing bio-inspired ligands is a subject of research interest because it will allow the preparation of new biocompatible (nano)particles able to penetrate at the cellular level, acting as liberators or transporters of substances of biological or pharmacological interest [21] and extend their possible uses to create multifunctional biologically-compatible nanodevices [22], catalytic nanoparticles [23], antimicrobial drugs [24], nanocarriers [13], or anticancer chemotherapy drugs [25].

Herein, we describe easy ways to control the size, from the micro- to the sub-micron-scale, of a bioinspired coordination polymer based on copper(II) with adenine (Ad) [26]. We have studied the reaction conditions (such as reaction time, concentration, and surfactants) in order to analyze their effects on the resulting size of the material. Additionally, we have studied the effect of the presence of ionic, non-ionic, and cationic surfactants in this reaction to modify the material size by selective interactions [27]. Moreover, stability studies over the time and in a $\mathrm{pH}$ range have also been carried out in order to determine/evaluate the shape and size of the changes [27]. Finally, the study of the magnetic properties comparing micro- and submicron particles has also been conducted.

\section{Experimental Section}

\subsection{Materials and Methods}

All reagents and solvents were purchased from standard chemical suppliers and used as received. Infrared (IR) spectra were recorded on a PerkinElmer 100 spectrophotometer (PerkinElmer Inc., Waltham, MA, USA) using a PIKE Technologies MIRacle Single Reflection Horizontal ATR Accessory from $4000-600 \mathrm{~cm}^{-1}$. Elemental analysis was performed on an LECO CHNS-932 Elemental Analyzer (LECO Corporation, St. Joseph, MI, USA). Powder X-ray diffraction has been collected using a Diffractometer PANalyticalX'Pert PRO $/ 2 \theta$ (PANanalytical, Almelo, The Netherlands) primary monochromator and detector with fast $X^{\prime}$ Celerator. Theoretical $X$-ray powder diffraction patterns were calculated using Mercury Cambridge Structural Database (CSD) version 3.6 software from the Crystallographic Cambridge Data Base (CCDC). The samples have been analysed with scanning $\theta / 2 \theta$. Magnetic measurements were done in a Quantum Design MPMS-XL-5 SQUID magnetometer (San Diego, CA, USA) in the 2-300 K temperature range with an applied magnetic field of $0.1 \mathrm{~T}$ in a water suspension of the sample. The susceptibility data were corrected for the sample holders previously measured under the same conditions, and for the diamagnetic contributions as deduced by using Pascal's constant tables [28].

FESEM images were recorded on a Philips XL30 S-FEG (Eindhoven, The Netherlands) field emission scanning electron microscope. 
SEM sample preparation of $\left\{\left[\mathrm{Cu}_{2}\left(\mu_{3} \text {-adeninato }\right)_{2}(\mu \text {-Hadip })_{2}\right]\right\}_{n}(\mathbf{1 n}): 0.017 \mathrm{~g}$ of $\mathbf{1 n}$ were suspended in $21 \mathrm{~mL}$ of water. $20 \mu \mathrm{L}$ of this suspension was diluted with $100 \mu \mathrm{L}$ of Milli-Q water. Then, $10 \mu \mathrm{L}$ of the diluted suspension was deposited on glass substrates by drop-casting and allowed to adsorb for $15 \mathrm{~min}$ at room temperature. The remaining suspension was removed blowing with an argon flow.

SEM samples preparation of surfactant-mediated $\left\{\left[\mathrm{Cu}_{2}\left(\mu_{3} \text {-adeninato }\right)_{2}(\mu \text {-Hadip })_{2}\right]\right\}_{\mathrm{n}}(\mathbf{1 n}): 0.017 \mathrm{~g}$ of $1 \mathrm{n}$ were suspended in $21 \mathrm{~mL}$ of water. $20 \mu \mathrm{L}$ of this suspension was diluted with $100 \mu \mathrm{L}$ of Milli-Q water. Then, $10 \mu \mathrm{L}$ of the diluted suspensions were deposited on glass substrates by drop-casting and allowed to adsorb for $15 \mathrm{~min}$ at room temperature. The remaining suspensions were removed by blowing with an argon flow.

Atomic force microscope (AFM) images were acquired in dynamic mode using a Nanotec Electronica system (NANOTEC, Madrid, Spain) operating at room temperature in ambient air conditions. For AFM measurements, Olympus cantilevers were used with a nominal force constant of $0.75 \mathrm{~N} / \mathrm{m}$ and a resonance frequency of about $70 \mathrm{kHz}$. The images were processed using WSxM [29]. The surfaces used for AFM were $\mathrm{SiO}_{2}, 300 \mathrm{~nm}$ in thickness (IMS Company). $\mathrm{SiO}_{2}$ surfaces were sonicated in an ultrasound bath at $37 \mathrm{KHz}$ and 380 Watts, for $15 \mathrm{~min}$ in acetone, $15 \mathrm{~min}$ in 2-propanol, and then dried under an argon flow.

AFM sample preparation of $\left\{\left[\mathrm{Cu}_{2}\left(\mu_{3} \text {-adeninato }\right)_{2}(\mu \text {-Hadip })_{2}\right]\right\}_{\mathrm{n}}(\mathbf{1 n}): 0.017 \mathrm{~g}$ of $\mathbf{1 n}$ were suspended in $21 \mathrm{~mL}$ of water. $100 \mu \mathrm{L}$ of this suspension was diluted with $1 \mathrm{~mL}$ of Milli-Q water. Then, $15 \mu \mathrm{L}$ of the diluted suspension was deposited on $\mathrm{SiO}_{2}$ substrates by drop-casting and allowed to adsorb for $15 \mathrm{~min}$ at room temperature. The remaining suspension was removed by blowing with an argon flow.

Size distribution and surface charge of the submicroparticles were measured by Dynamic Light Scattering (DLS), using a ZetasizerNano-ZS instrument (Malvern Instruments, Malvern, UK), and a Vasco 1 particle size analyser of Cordouan Technologies. The size range limit (diameter) is $0.3 \mathrm{~nm}$ to $10 \mu \mathrm{m}$ ( $3.8 \mathrm{~nm}$ to $10 \mu \mathrm{m}$ for zeta-potential). Note: the diameter measured by DLS is the hydrodynamic diameter. The samples were comprised of aqueous dispersions of the submicroparticles in distilled water. All samples were diluted to obtain an adequate submicroparticle concentration. To study the influence of $\mathrm{pH}$ on zeta-potential, the $\mathrm{pH}$ of sample was modified by $\mathrm{HCl}(0.01 \mathrm{M})$ solution $(\mathrm{pH}=5.0-5.9)$.

\subsection{Synthesis}

\subsubsection{Synthesis of $\left\{\left[\mathrm{Cu}_{2}\left(\mu_{3} \text {-adeninato }\right)_{2}(\mu \text {-Hadip })_{2}\right]\right\}_{\mathrm{n}}(\mathbf{1 m})$}

Green microcrystals of compounds $1 \mathrm{~m}$ were prepared by slow diffusion of a methanolic solution $(5 \mathrm{~mL})$ of $0.2 \mathrm{mmol}$ of adipic acid $(0.0295 \mathrm{~g})$ into an aqueous solution of $0.2 \mathrm{mmol}$ of $\mathrm{Cu}\left(\mathrm{NO}_{3}\right)_{2} \cdot 3 \mathrm{H}_{2} \mathrm{O}(0.0483 \mathrm{~g}, 5 \mathrm{~mL})$ and $0.2 \mathrm{mmol}$ of adenine $(0.0273 \mathrm{~g}, 20 \mathrm{~mL})$ as previously reported [26] (0.096 g, 70\% yield based on metal). Anal. Calcd. (\%). (found) for $\mathrm{C}_{22} \mathrm{H}_{26} \mathrm{Cu}_{2} \mathrm{~N}_{10} \mathrm{O}_{8}(685.62 \mathrm{~g} / \mathrm{mol})$ : C, 38.54 (38.33); H, 3.82 (4.02); N, 20.43 (20.06); IR ( $\mathrm{cm}^{-1}$, KBr pellet): 3410 (s), 3350 (m), 3210 (m), $2940(\mathrm{~m}), 1710(\mathrm{~m}), 1655(\mathrm{~s}), 1615(\mathrm{~m}), 1580(\mathrm{~s}), 1538(\mathrm{~m}), 1466(\mathrm{w}), 1452(\mathrm{w}), 1400(\mathrm{~m}), 1385(\mathrm{w}), 1344(\mathrm{w})$, $1316(\mathrm{~m}), 1280(\mathrm{w}), 1238(\mathrm{w}), 1205(\mathrm{~m}), 1155(\mathrm{~m}), 1037(\mathrm{w}), 1014(\mathrm{w}), 991(\mathrm{w}), 921(\mathrm{w}), 899(\mathrm{w}), 866(\mathrm{w})$, $792(\mathrm{~m}), 740(\mathrm{w}), 649(\mathrm{~m}), 600(\mathrm{~m})$. X-ray power diffraction confirmed its purity and structure.

\subsubsection{Synthesis of Submicron $\left\{\left[\mathrm{Cu}_{2}\left(\mu_{3} \text {-adeninato }\right)_{2}(\mu \text {-Hadip })_{2}\right]\right\}_{n}(\mathbf{1 n})$}

A mixture of an aqueous solution $\left(25^{\circ} \mathrm{C}, 4 \mathrm{~mL}\right)$ of adipic acid ( $\mathrm{H}_{2}$ adip) $(0.2 \mathrm{mmol}, 0.0295 \mathrm{~g})$, an aqueous solution $\left(25^{\circ} \mathrm{C}, 4 \mathrm{~mL}\right)$ of $\mathrm{Cu}\left(\mathrm{NO}_{3}\right)_{2} \cdot 3 \mathrm{H}_{2} \mathrm{O}(0.2 \mathrm{mmol}, 0.0483 \mathrm{~g})$ and an aqueous solution $\left(25^{\circ} \mathrm{C}, 13 \mathrm{~mL}\right)$ of adenine $(0.2 \mathrm{mmol}, 0.0273 \mathrm{~g})$ was stirred for $5 \mathrm{~min}$ at $40^{\circ} \mathrm{C}(\mathrm{pH}=5.8)$. After that, the resulting deep-blue suspension was allowed to stand at $25^{\circ} \mathrm{C}$ for $20 \mathrm{~h}$ and during this time is turned onto a green suspension. Finally, the suspension was centrifuged for $5 \mathrm{~min}$ at $10000 \mathrm{rpm}$. The green solid obtained was washed four times with $1 \mathrm{~mL}$ of water and dried under vacuum $(0.017 \mathrm{~g}$, $13 \%$ yield). Anal. Calcd. (\%) (found) for $\mathrm{C}_{22} \mathrm{H}_{26} \mathrm{Cu}_{2} \mathrm{~N}_{10} \mathrm{O}_{8}(685.62 \mathrm{~g} / \mathrm{mol}$ ): C, 38.54 (38.90); $\mathrm{H}, 3.82$ (3.91); $\mathrm{N}, 20.43$ (19.65). IR selected data $\bar{v}\left(\mathrm{~cm}^{-1}\right): 3345$ (s), $3172(\mathrm{~s}), 2962(\mathrm{~m}), 1718(\mathrm{~m}), 1666$ (s), 1619 (s), 
1577 (s), 1538 (m), 1463 (m), 1452 (m), 1398 (m), 1342 (m), 1315 (m), 1280 (m), 1213 (m), 1155 (m), $1079(\mathrm{w}), 937(\mathrm{w}), 900(\mathrm{w}), 792(\mathrm{~m}), 775(\mathrm{~m}), 649(\mathrm{~m})$. X-ray powder diffraction confirmed the structure of the sample.

\subsubsection{Surfactant-Mediated Syntheses of Submicron $\left\{\left[\mathrm{Cu}_{2}\left(\mu_{3} \text {-adeninato }\right)_{2}(\mu \text {-Hadip })_{2}\right]\right\}_{\mathrm{n}}(\mathbf{1 n})$}

Stock solutions of 1,5 , and $15 \mathrm{mM}$ sodium dodecyl sulfate (SDS), cetyltrimethylammonium bromide $(\mathrm{CTAB})$, and 1,5 , and $15 \mathrm{~g} / \mathrm{L}$ of polyethylene glycol $\left(\mathrm{P}_{123} ; \mathrm{M}=5800\right)$ were prepared in water.

For each concentration of surfactant the synthetic procedure is as follows:

$\mathrm{Cu}\left(\mathrm{NO}_{3}\right)_{2} \cdot 3 \mathrm{H}_{2} \mathrm{O}(0.2 \mathrm{mmol}, 0.0483 \mathrm{~g})$ and adenine $(0.2 \mathrm{mmol}, 0.0273 \mathrm{~g})$ were dissolved in 4 and $13 \mathrm{~mL}$ of the stock surfactant solution, respectively, and both solutions mixed. Then, adipic acid ( $\mathrm{H}_{2}$ adip) $(0.2 \mathrm{mmol}, 0.0295 \mathrm{~g})$ was dissolved in $4 \mathrm{~mL}$ of the stock surfactant solution at $25{ }^{\circ} \mathrm{C}$ and added to the initial $\mathrm{Cu}\left(\mathrm{NO}_{3}\right)_{2} \cdot 3 \mathrm{H}_{2} \mathrm{O}$ and adenine solution. After that, the mixture was stirred for $5 \mathrm{~min}$ at $40{ }^{\circ} \mathrm{C}$, and the resulting deep blue suspensions were then stored at $25^{\circ} \mathrm{C}$ for $20 \mathrm{~h}$. During this time it turned deep purple for $\mathrm{CTAB}$, purple for SDS, and green for $\mathrm{P}_{123}$. Finally, each suspension was centrifuged for $10 \mathrm{~min}$ at $5000 \mathrm{rpm}$ and the solids washed four times with $1 \mathrm{~mL}$ of water each time and dried under vacuum.

\section{Results and Discussion}

Formation of coordination polymers typically consists of a one-step process based on precipitation when a poor solvent is used or when the concentration of the $\mathrm{CP}$ is suitable. This simple procedure can directly originate the nanostructuration of the material. The synthesis and structure of compound $\left\{\left[\mathrm{Cu}_{2}\left(\mu_{3} \text {-adeninato }\right)_{2}(\mu \text {-Hadip })_{2}\right]\right\}_{\mathrm{n}} 5 \mathrm{H}_{2} \mathrm{O}(\mathbf{1 m})$ was previously reported [26]. However, in this case the preparation of $1 \mathrm{~m}$ seems to take place in a two-step process in which, first, the dinuclear complex $\left[\mathrm{Cu}_{2}(\mu-\mathrm{N} 3 \text {,N9-adeninato })_{4}\left(\mathrm{H}_{2} \mathrm{O}\right)_{2}\right]$ seems to be formed in suspension (Figure 1$)$, as is shown by its IR spectra (Table S1) and evolves to $1 \mathrm{~m}$ [30].

The interesting structure of $\left\{\left[\mathrm{Cu}_{2}\left(\mu_{3} \text {-adeninato }\right)_{2}(\mu \text {-Hadip })_{2}\right]\right\}_{n}$ consists of a three-dimensional coordination polymer where the $\mathrm{Cu}$ (II) centers are linked by tridentate adenine ligands (N3, N7, N9) and the carboxylate anions act as bidentate ligands $(\mu-\mathrm{kO} 1: \mathrm{kO} 2)$. Interestingly, the structure shows the presence of free amino groups corresponding to the un-coordinated adenine $\mathrm{N}(6) \mathrm{H}_{2}$ and free carboxyl groups placed within the channels (Figure 2) [26]. However, despite its interesting structural features and potential applications, its potential nano-structuration has not yet been studied.
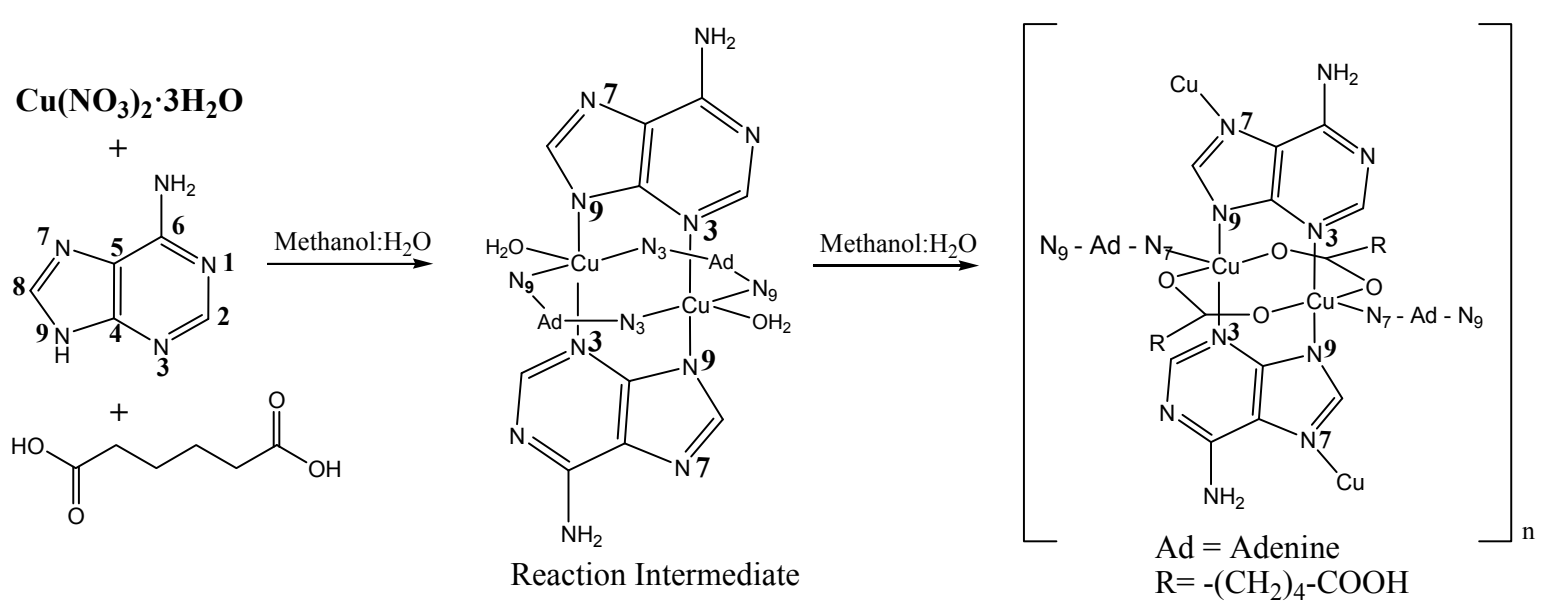

Figure 1. Synthesis scheme of $\left\{\left[\mathrm{Cu}_{2}\left(\mu_{3} \text {-adeninato }\right)_{2}(\mu \text {-Hadip })_{2}\right]\right\}_{\mathrm{n}}(\mathbf{1 m})$ through the intermediate $\left[\mathrm{Cu}_{2}(\mu-\mathrm{N} 3, \mathrm{~N} 9 \text {-adeninato })_{4}\left(\mathrm{H}_{2} \mathrm{O}\right)_{2}\right]$. 

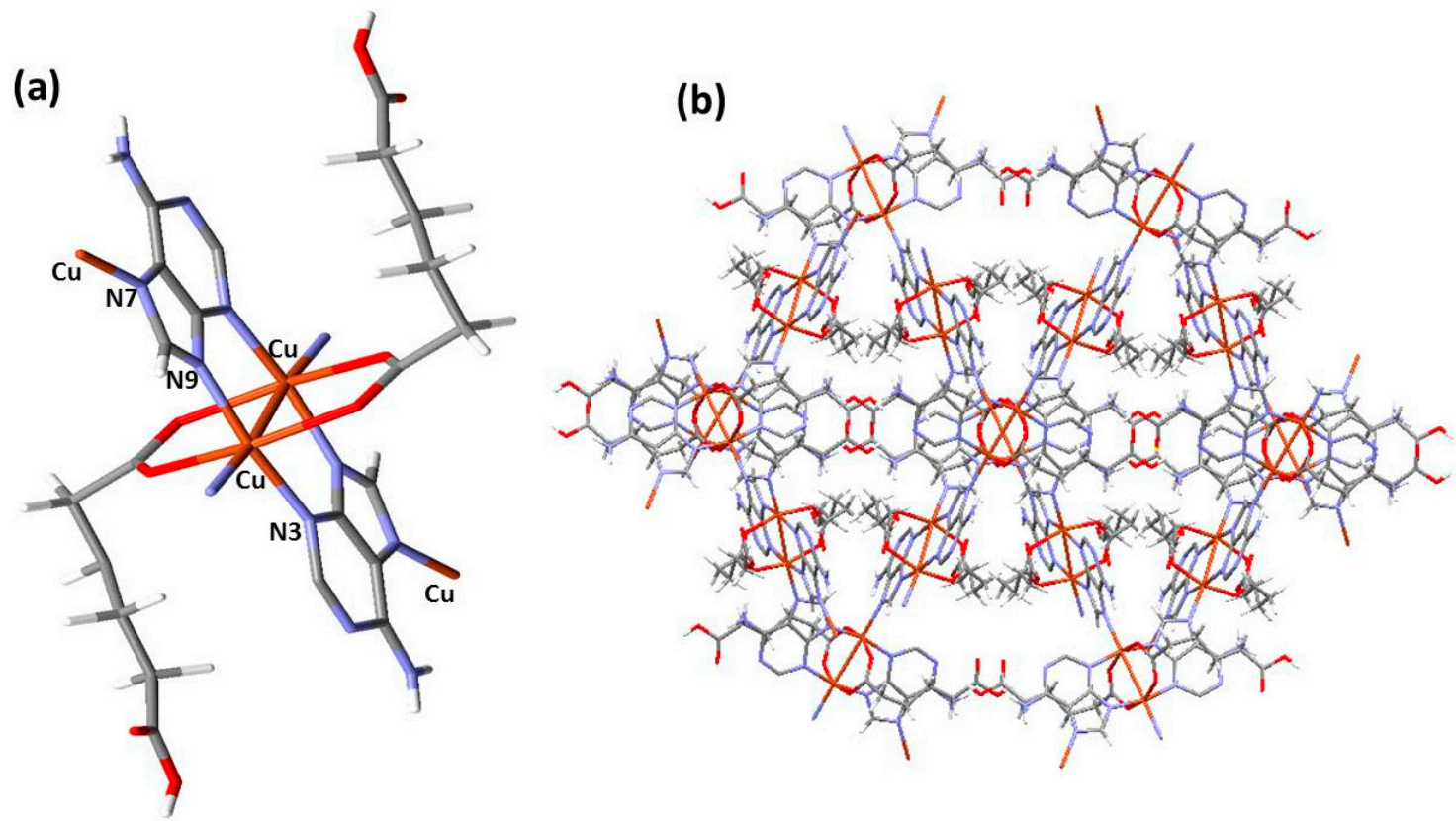

Figure 2. Different views of the structure of $\left\{\left[\mathrm{Cu}_{2}\left(\mu_{3} \text {-adeninato }\right)_{2}(\mu \text {-Hadip })_{2}\right]\right\}_{\mathrm{n}}(\mathbf{1 m})$ (ref. code KEBPOY from the Cambridge Structural Database, CSD) [26]. (a) Fragment of the repetition unit of compound $1 \mathrm{~m}$ that shows the paddle-wheel motif. To clarify nitrogen atoms are in blue, copper atoms are in orange, carbon atoms are in grey, oxygen atoms are in red, and hydrogens atoms are in white. (b) The perspective view of the overall 3D structure. The structural disorder has been omitted in the drawing for clarity.

3.1. Effect of Temperature, Reaction Time and Concentration in the Size and Shape of $\left\{\left[C u_{2}\left(\mu_{3} \text {-adeninato }\right)_{2}\right.\right.$ $\left.\left.(\boldsymbol{\mu} \text {-Hadip })_{2}\right]\right\}_{n}(\mathbf{1 n})$

An analysis of the green single crystals of $\mathbf{1 m}$ obtained following the previously-reported synthesis carried out by slow diffusion of a methanolic solution of adipic acid $\left(\mathrm{H}_{2}\right.$ adip) into an aqueous $\mathrm{Cu}\left(\mathrm{NO}_{3}\right)_{2} \cdot 3 \mathrm{H}_{2} \mathrm{O}$ and adenine solution in a 1:1:1 stoichiometry (Figure 1) [26] give rise to the isolation of octahedral micron size crystals formed by slow liquid-liquid diffusion after several days (Figure 3).

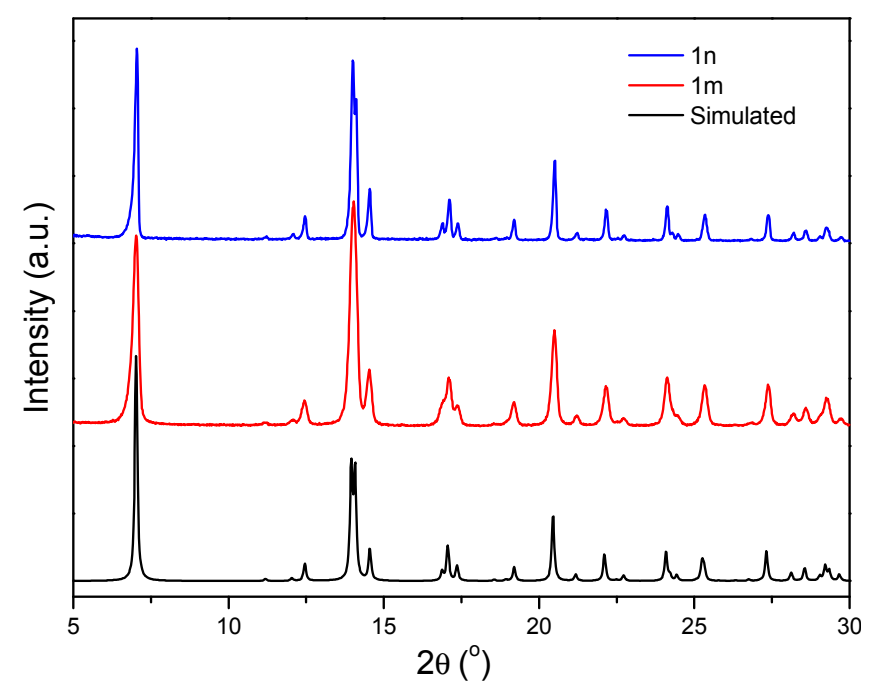

Figure 3. X-ray powder diffraction patterns of simulated from DRX data from the single crystal structural elucidation of $\left\{\left[\mathrm{Cu}_{2}\left(\mu_{3} \text {-adeninato }\right)_{2}(\mu \text {-Hadip })_{2}\right]\right\}_{n}$ (black line), (1m) microcrystalline compound (red line), and (1n) submicroparticles (blue line). 
We have first decided to analyse the effect of the temperature and reaction time over the particle size [30]. In our approach, adenine, adipic acid, and copper(II) are dissolved in water by heating during some minutes and, later, the solution is stored for $20-24 \mathrm{~h}$ at $20{ }^{\circ} \mathrm{C}$ to produce $\left\{\left[\mathrm{Cu}_{2}\left(\mu_{3} \text {-adeninato }\right)_{2}(\mu \text {-Hadip })_{2}\right]\right\}_{n}$. During the heating the initial blue solution turned into a green suspension indicating a change in the coordination sphere of the $\mathrm{Cu}(\mathrm{II})$ cation.

The two syntheses carried out upon heating at 40 and $90{ }^{\circ} \mathrm{C}$ for $15 \mathrm{~min}$ afforded octahedral particles, where the size of those obtained at $90{ }^{\circ} \mathrm{C}$ had dimensions of ca. $1.2 \pm 0.3 \mu \mathrm{m}$ (Table 1 , experiment $a$, Figure 4a), while a significant shortening in size of $381 \pm 63 \mathrm{~nm}$ (Table 1, experiment $b$, Figure $4 \mathrm{~b}$ ) is observed when heating at $40{ }^{\circ} \mathrm{C}$. Other experiments conducted at $40^{\circ} \mathrm{C}$ and varying the reaction time do not show significant changes in the octahedral sizes (Table 1, experiments $b$ and $c$ ). Similarly, experiments carried out at higher concentrations do not show significant variations in both shape and size (Table 1, experiments $d-h$ ).

Therefore, it seems that the reaction temperature is critical to produce a significant enhancement in the size of the particles. In view of the low yield obtained in experiment $a$ ( $7 \%$ yield), we postulated that an increase in the temperature of the process $\left(90^{\circ} \mathrm{C}\right)$, could cause partial rupture of the intermediate dimer or partial esterification of the adipic acid [31] (Figure 1), reducing the concentration of the precursors, which would favour an increase in particle size.

Table 1. Reaction conditions to get $\left\{\left[\mathrm{Cu}_{2}\left(\mu_{3} \text {-adeninato }\right)_{2}(\mu \text {-Hadip })_{2}\right]\right\}_{n}$ and particle size at $\mathrm{pH} 5.8$.

\begin{tabular}{ccccccc}
\hline Experiment & $\begin{array}{c}\mathbf{T} \\
\left({ }^{\circ} \mathbf{C}\right)\end{array}$ & $\begin{array}{c}\text { Reaction Time } \\
(\mathbf{m i n})\end{array}$ & $\begin{array}{c}\text { Adenine } \\
(\mathbf{M})\end{array}$ & $\begin{array}{c}\mathbf{C u}\left(\mathbf{N O}_{\mathbf{3}} \mathbf{~}_{\mathbf{2}} \cdot \mathbf{3 H}_{\mathbf{2}} \mathbf{O}\right. \\
\mathbf{( M )}\end{array}$ & $\begin{array}{c}\text { Adipic Acid } \\
(\mathbf{M})\end{array}$ & $\begin{array}{c}\text { Particle Size } \\
\mathbf{( n m})\end{array}$ \\
\hline$a$ & 90 & 15 & 0.010 & 0.040 & 0.040 & $1200 \pm 255$ \\
$b$ & 40 & 15 & 0.015 & 0.040 & 0.040 & $381 \pm 63$ \\
$c$ & 40 & 5 & 0.015 & 0.040 & 0.040 & $403 \pm 130$ \\
$d$ & 40 & 5 & 0.015 & 0.050 & 0.040 & $470 \pm 117$ \\
$e$ & 40 & 5 & 0.015 & 0.050 & 0.050 & $340 \pm 70$ \\
$f$ & 40 & 5 & 0.040 & 0.040 & 0.040 & $521 \pm 190$ \\
$g$ & 40 & 5 & 0.040 & 0.080 & 0.040 & $580 \pm 107$ \\
$h$ & 40 & 5 & 0.040 & 0.040 & 0.080 & $465 \pm 170$ \\
\hline
\end{tabular}

${ }^{1}$ The means and standard deviations were calculated from values corresponding to 60 particles from SEM images.
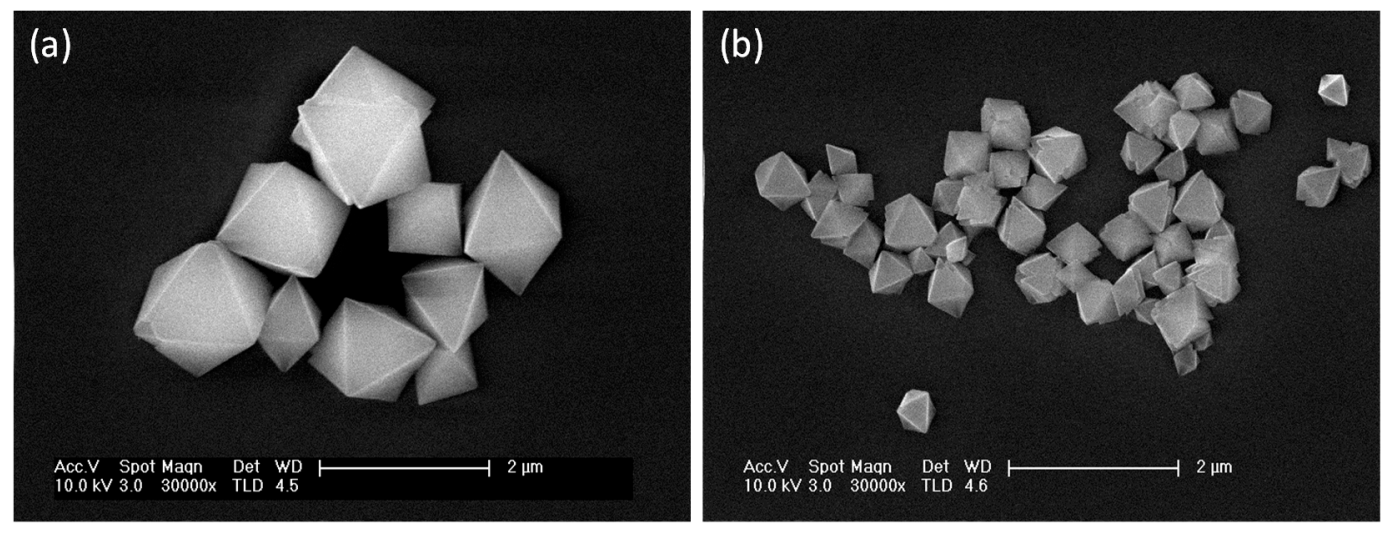

Figure 4. FESEM images of $\left.\left\{\left[\mathrm{Cu}_{2}\left(\mu_{3} \text {-adeninato }\right)_{2} \text { ( } \mu \text {-Hadip) }\right)_{2}\right]\right\}_{\mathrm{n}}$ : (a) octahedral $1.2 \pm 0.3$ micrometre particles obtained from experiment $a$; and (b) octahedral $403 \pm 130 \mathrm{~nm}$ particles obtained from experiment $c$.

Atomic force microscopy (AFM) study has been used to complete the morphological characterization of the submicron octahedral 1n particles, obtained in the experiment $c$ (Figure 5).

Additionally, stability studies of $\mathbf{1 n}$ in aqueous solutions with the time and at physiological $\mathrm{pHs}$ have been carried out. This is an important aspect toward the potential use of these submicron-particles for instance under biological conditions. Thus, sub-micron-particles of $\mathbf{1 n}$ at $\mathrm{pH} 5.8$ are stable, retaining 
their morphological features, with sizes of ca. $400 \mathrm{~nm}$, and shape, for at least one month (Figure 6). Moreover, $\mathbf{~} \mathrm{n}$ is also stable at $\mathrm{pHs}$ between 5.5 and 7 without significant changes in size and shape modifications for 534-471 \pm 84 (Figure 7). However, almost immediately, decomposition of $\mathbf{1 n}$ is observed at pHs lower than 5.5 and higher than 7 (Figure S1).
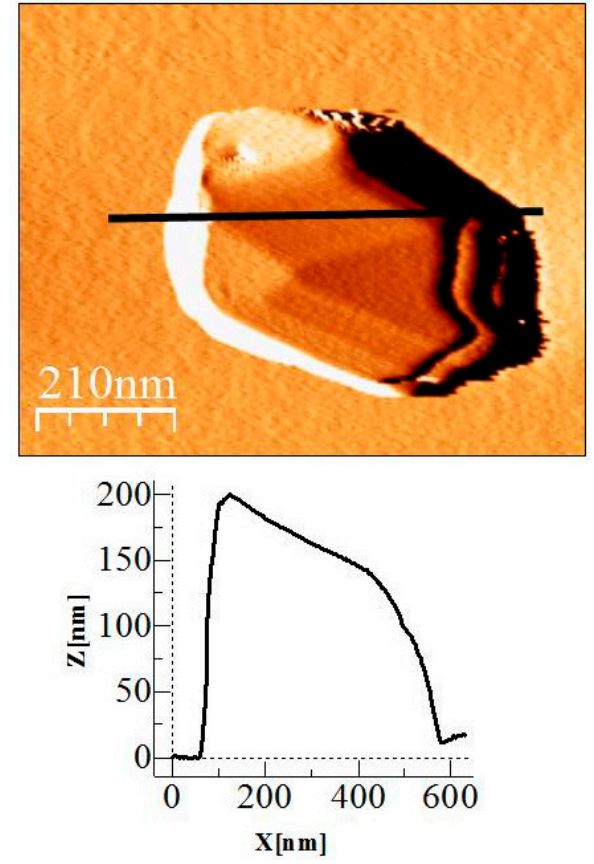
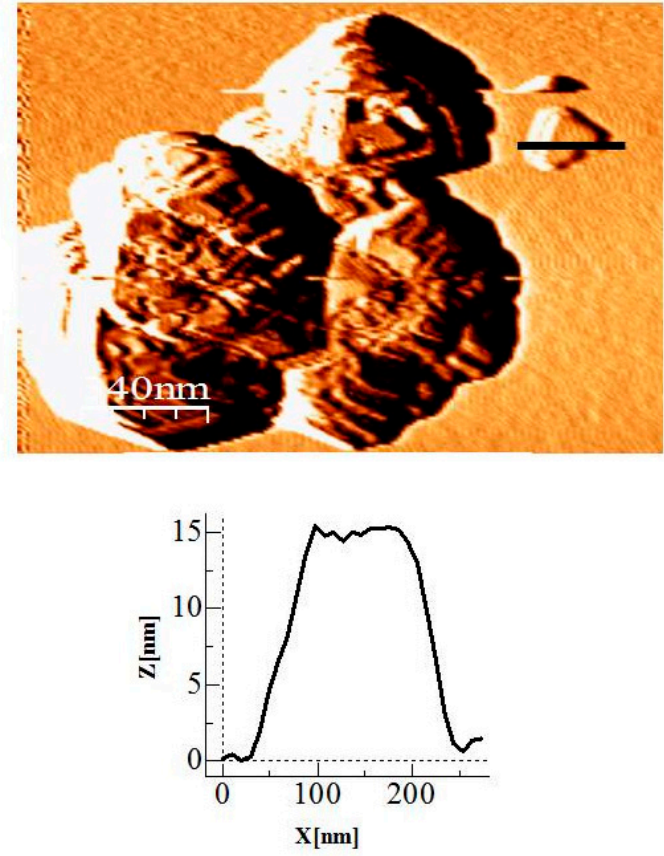

Figure 5. AFM images of $\left\{\left[\mathrm{Cu}_{2}\left(\mu_{3} \text {-adeninato }\right)_{2}(\mu \text {-Hadip })_{2}\right]\right\}_{n}(\mathbf{1 n})$ obtained in experiment $c$ : Octahedral sub-micrometer and nanometer particles sizes (top); and the corresponding height profiles along the lines (bottom).
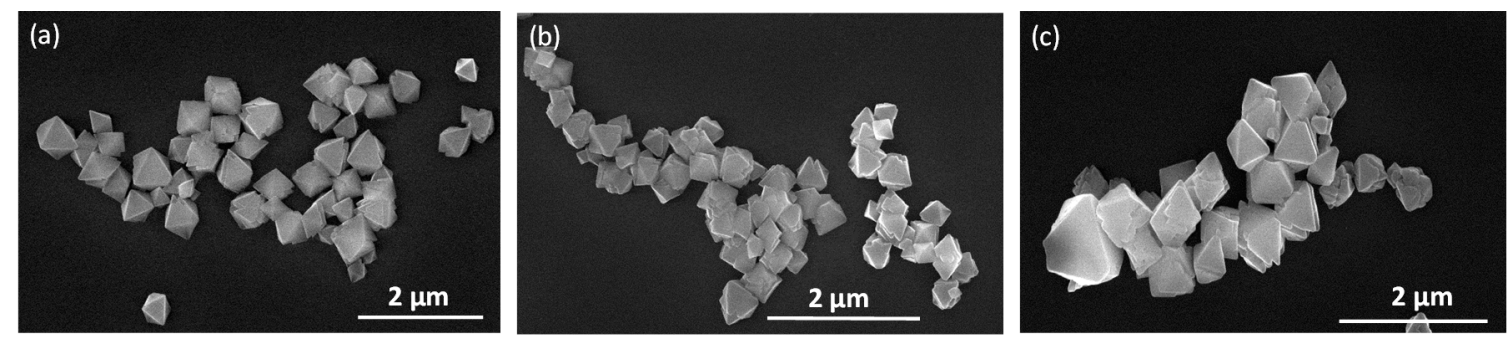

Figure 6. (a) FESEM images of sub-microparticles of compound 1n with an average size of $403 \pm 130 \mathrm{~nm}$ obtained heating at $40{ }^{\circ} \mathrm{C}$ for $5 \mathrm{~min}$ and leaving the solution $20 \mathrm{~h}$ at $25^{\circ} \mathrm{C}$; (b) 1 n sample stored for one week at $25^{\circ} \mathrm{C}$, with an average size of $467 \pm 52 \mathrm{~nm}$; and (c) 1n sample stored for one month at $25^{\circ} \mathrm{C}$ with an average size of $484 \pm 28 \mathrm{~nm}$. The means and standard deviations were calculated from values corresponding to 60 particles from FESEM images. 

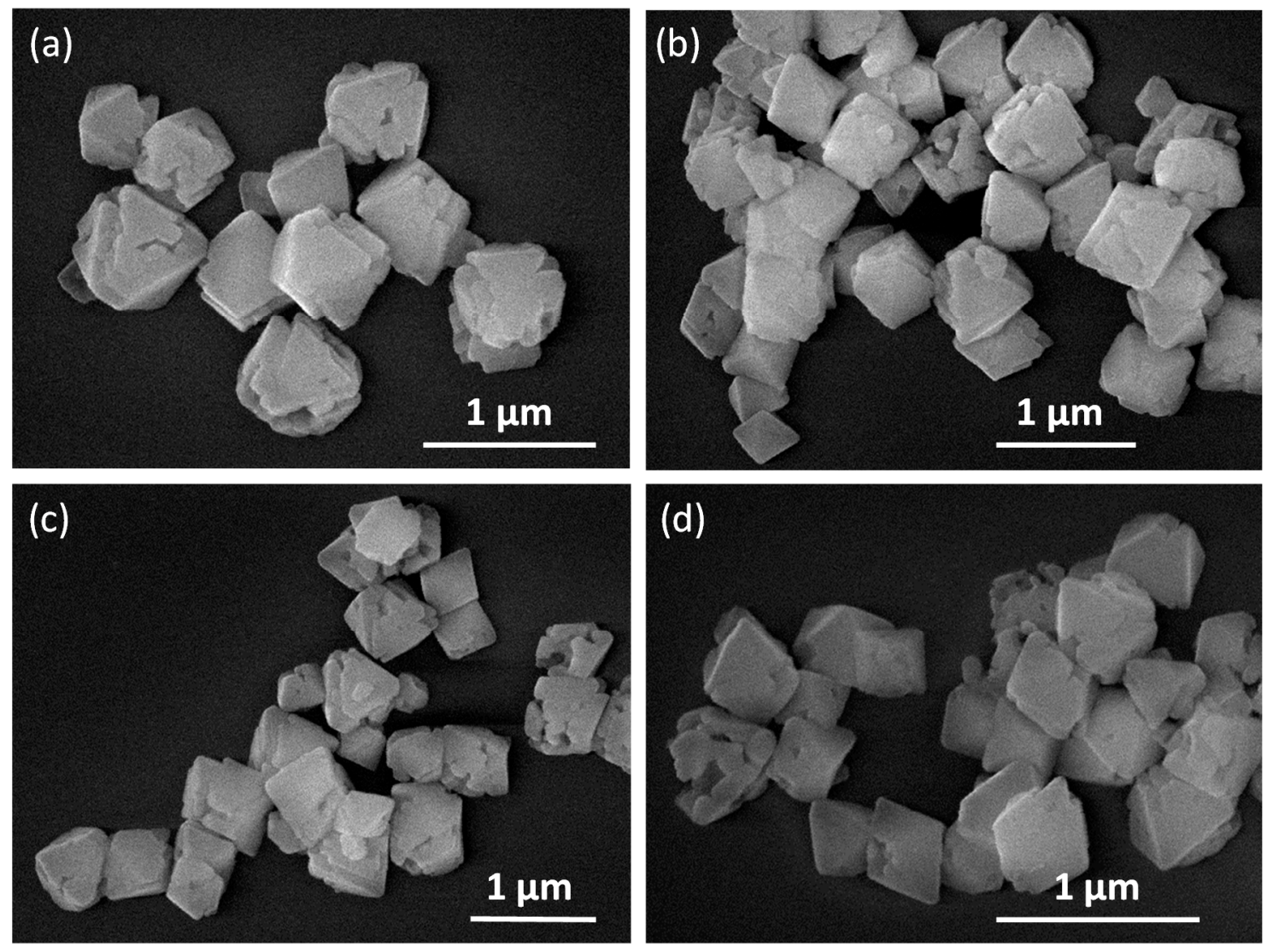

Figure 7. FESEM images showing the stability of $1 \mathrm{n}$ obtained heating at $40{ }^{\circ} \mathrm{C}, 5 \mathrm{~min}$ and leaving the solution $20 \mathrm{~h}$ at $25{ }^{\circ} \mathrm{C}$ (c experimental conditions) versus $\mathrm{pH}$ : (a) $\mathrm{pH}=5.5$, average size of $534 \pm 85 \mathrm{~nm}$ (b) $\mathrm{pH}=5.7$, average size of $480 \pm 93 \mathrm{~nm}$; (c) $\mathrm{pH}=5.9$, average size of $474 \pm 85 \mathrm{~nm}$; and (d) $\mathrm{pH}=7$, average size of $471 \pm 84 \mathrm{~nm}$. The means and standard deviations were calculated from values corresponding to 60 particles from FESEM images.

\subsection{Effect of Surfactant in the Size and Shape of $\left\{\left[C u_{2}\left(\mu_{3} \text {-Adeninato }\right)_{2}(\mu \text {-Hadip })_{2}\right]\right\}_{n}(\mathbf{1 n})$}

The surfactants usually have a template role in the particle formation and their action mechanism, in the final size and shape of the $\mathrm{CP}$ material, and may also depend on the surfactant character-ionic, cationic, or neutral-which can cause competition between electrostatic interactions such as surfactant and metal ion, hydrophobic interactions, and coordination interactions [32]. Most of them are affected by the surfactant concentration. Moreover, it has been previously described that the binding strength of the surfactant ligands to different facets of the nanocrystals can control the relative growth rates and then the geometry of the nanoparticles. Typically, the surfactants selectively absorbed on some facets of the nanocrystal nuclei and altered the surface free energy of the absorbed plane, leaving a faster growth speed of the unabsorbed plane and, thus, induced oriented growth to the final product [27].

In order to study the size variation of compound $1 \mathrm{n}$ in the presence of different types of surfactants at different concentrations, we have selected the surfactants looking for different types of interactions with $\left\{\left[\mathrm{Cu}_{2}\left(\mu_{3} \text {-adeninato }\right)_{2}(\mu \text {-Hadip })_{2}\right]\right\}_{\mathrm{n}}$. As we have already stated, the structure of $\left\{\left[\mathrm{Cu}_{2}\left(\mu_{3} \text {-adeninato }\right)_{2}(\mu \text {-Hadip })_{2}\right]\right\}_{n}$ shows free acid groups corresponding to adipic acid and adenine ligands with free $\mathrm{NH}_{2}$ groups (Figure 1). In order to determine the net surface charge of $\left\{\left[\mathrm{Cu}_{2}\left(\mu_{3} \text {-adeninato }\right)_{2}(\mu \text {-Hadip })_{2}\right]\right\}_{n}$, we have measured the $\mathrm{Z}$ potential of a $\mathbf{1 n}$ suspension (Table 1 , experiment $c$ ) at different $\mathrm{pH}$ values, from 5.5 to 7 , in which $1 \mathrm{n}$ is stable. The positive $Z$ values (12-30 $\mathrm{mV}$, Figure 8) obtained confirm that the net surface charge of $\mathbf{1 n}$ presents a positive charge probably due to the protonation of amino groups [33]. 


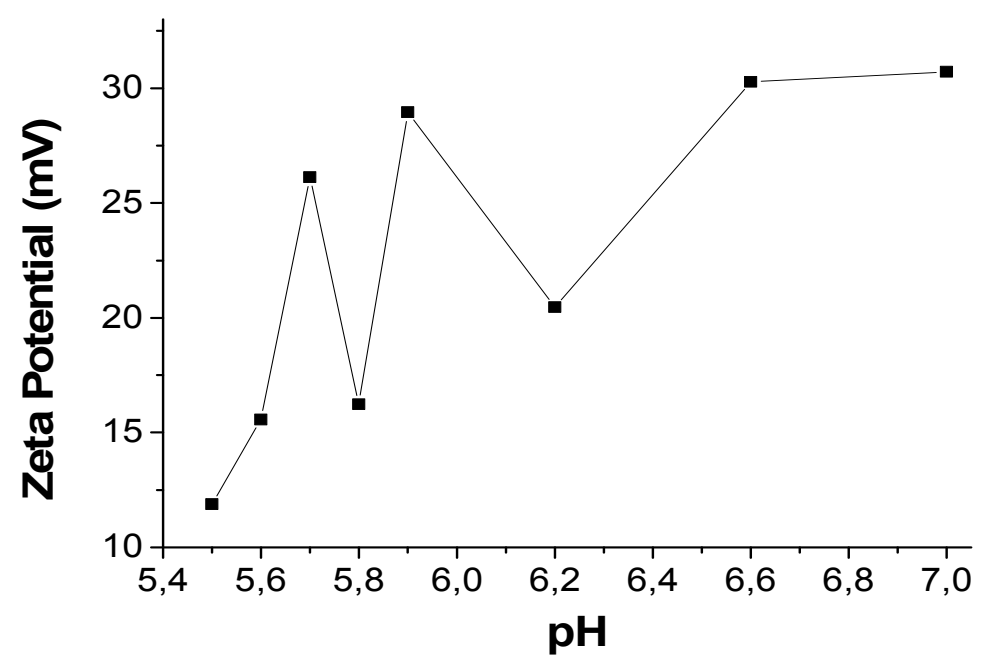

Figure 8. Z-potential values of $\mathbf{1 n}$ at different $\mathrm{pHs}$.

Taking into account these considerations, the interaction of $\mathbf{1 n}$ with different ionic surfactants, at suitable concentrations, could produce the following changes in its size: (i) an anionic surfactant, should change the $Z$-potential value from positive to negative, due to the electrostatic interactions and charge neutralization [34]; (ii) the electrostatic attractions between particle and surfactant should avoid the interaction between other particles avoiding the particle aggregation (hampering the particle growth); (iii) the interaction with a positively-charged surfactant should produce positive changes in the Z-potential and, therefore, electrostatic repulsions between the surfactant and the particle, which would favour the interactions leading aggregation between particles of $\mathbf{1 n}$, increasing the particle size; and (iv) the use of a neutral surfactant is not expected to produce any remarkable changes in Z-potential and, therefore, no significant changes in the particle size.

In order to corroborate these hypotheses, we have studied the interaction of $\mathbf{1 n}$, (obtained as in experiment $c$ ) with different surfactants; SDS (anionic), CTAB (cationic), and $\mathrm{P}_{123}$ (neutral) and at different concentrations (Table 2 and Table S2 and Figures S3-S7).

Table 2. Influence of different surfactants in the dimensions of $\left\{\left[\mathrm{Cu}_{2}\left(\mu_{3} \text {-adeninato }\right)_{2}(\mu-\mathrm{Hadip})_{2}\right]\right\}_{\mathrm{n}}$.

\begin{tabular}{cccccc}
\hline Surfactant & Z-Potential $\mathbf{( m V )}$ & $\mathbf{p H}$ & Surfactant Type & Surfactant Concentration & Particle Size $^{\mathbf{1}}(\mathbf{n m})$ \\
\hline No surfactant & 17 & 5.8 & - & - & $403 \pm 130$ \\
SDS & 8 & 5.6 & Anionic & $1 \mathrm{mM}$ & $422 \pm 55$ \\
CTAB & 42 & 6.9 & Cationic & $1 \mathrm{mM}$ & $2701 \pm 265$ \\
P123 & 21 & 5.8 & Neutral & $1 \mathrm{~g} / \mathrm{L}$ & $524 \pm 212$ \\
P123 & - & - & Neutral & $5 \mathrm{~g} / \mathrm{L}$ & $283 \pm 81$ \\
P123 & - & - & Neutral & $15 \mathrm{~g} / \mathrm{L}$ & $296 \pm 68$
\end{tabular}

${ }^{1}$ The means and standard deviations were calculated from values corresponding to 60 particles from the SEM images.

First, the synthesis of $\left\{\left[\mathrm{Cu}_{2}\left(\mu_{3} \text {-adeninato }\right)_{2}(\mu \text {-Hadip })_{2}\right]\right\}_{n}$, carried out at different concentrations of SDS and CTAB, shows that at low concentration, $1 \mathrm{mM}$, the generated material shows the expected structure corresponding to $\left\{\left[\mathrm{Cu}_{2}\left(\mu_{3} \text {-adeninato }\right)_{2}(\mu \text {-Hadip })_{2}\right]\right\}_{n}$ as confirmed by $\mathrm{X}$-ray powder diffraction (Figures S3-S6), while higher concentrations of ionic surfactants produce side reactions, as verified spectroscopically and by X-ray diffraction giving rise to a mixture of products. However, in the case of the use of $\mathrm{P}_{123}, \mathrm{X}$-ray powder diffraction confirms the structure $\left\{\left[\mathrm{Cu}_{2}\left(\mu_{3} \text {-adeninato }\right)_{2}(\mu \text {-Hadip })_{2}\right]\right\}_{\mathrm{n}}$, which is not altered independently of the $\mathrm{P}_{123}$ concentration (Figure 9 and Figure S7). 


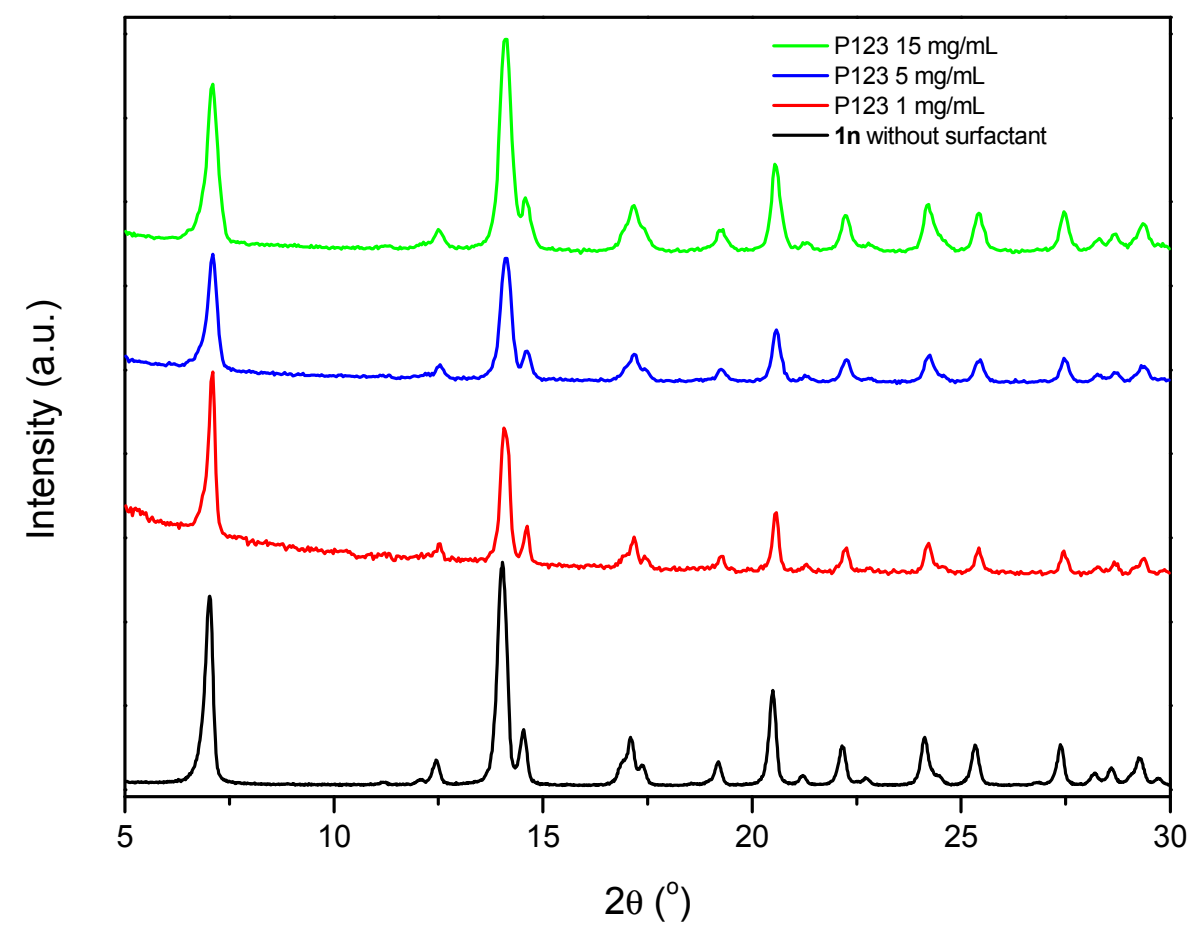

Figure 9. X-ray powder diffraction patterns of $\left\{\left[\mathrm{Cu}_{2}\left(\mu_{3} \text {-adeninato }\right)_{2}(\mu \text {-Hadip })_{2}\right]\right\}_{n}(\mathbf{1 n})$ (black) and the obtained products under different concentrations of the $\mathrm{P}_{123}$ surfactant.

Therefore, we focus on the synthesis of the material at low ionic surfactant concentrations to avoid an excess of the surfactant and side reactions. In particular, the reaction carried out with $1 \mathrm{mM}$ SDS produced a decrease in the $Z$ value with no significant change in the particle size to that obtained in experiment c (Table 2, Figure S3). However, the reaction carried out with $1 \mathrm{mM} \mathrm{CTAB}$ produces an increase in the $\mathrm{pH}$ value, up to 6.9 , and an enhance in the $\mathrm{Z}$ value which favours the particle aggregation, giving rise to a remarkable increase in the overall particle size to ca. 3 microns but retaining the shape (Table 2, Figure S5).

Finally, the reaction carried out with the neutral $P_{123}$ surfactant, at $1 \mathrm{~g} / \mathrm{L}$, does not produce any significant change in the $\mathrm{Z}$ potential value, generating octahedral sub-microparticles (Table 2 and Figure S7). Above the critical surfactant concentrations ( 5 and $15 \mathrm{mg} / \mathrm{mL}$ ), $\mathrm{P}_{123}$ decreases the size of the particles, probably due to it having terminal $\mathrm{OH}$ groups (Figure S7) which may favour particle-surfactant hydrogen bond interactions with the free adipic acid carboxylic groups present in compound $1 \mathrm{n}$, which results in a decrease in the particle-particle interactions (Table 2).

\subsection{Magnetic Properties}

The thermal variation of the product of the molar magnetic susceptibility versus the temperature per $\mathrm{Cu}$ dimer shows very similar results for both samples (1m and $\mathbf{1 n}$ ) (Figure S8) with a strong antiferromagnetic $\mathrm{Cu}-\mathrm{Cu}$ interaction. These results are very similar to those found in the crystalline sample [26] and confirm the presence of the same type of $\mathrm{Cu}$ (II) dimers with the same structure. We can also observe that there is no a noticeable change in the magnetic parameters in the range studied when the size of the nanoparticles are reduced (Figure S8).

\section{Conclusions}

Bio-inspired CPs present potentially outstanding applications in medical, pharmacological, and cosmetics fields. These applications require the formation of stability to physiological conditions and 
well-controlled sub-micron and/or nanoparticle sizes. Therefore, studies focusing on size reduction to produce homogeneous particles with defined morphologies are necessary.

In this work, we have selected a copper(II) coordination complex based on adenine, a potentially biocompatible ligand, with molecular recognition capabilities thanks to the presence of free amino and carboxyl groups in its structure.

The control of the reaction parameters, such as reaction temperature, allows the reduction of the particle size from the micron to the sub-micron scale. Interestingly, the reactions carried out in the presence of selected surfactants show remarkable phenomena. Thus, the presence of controlled amounts of neutral surfactant $\mathrm{P}_{123}$, with terminal $\mathrm{OH}$ groups in its structure, allows the reduction of the particle size to a few hundreds of nanometres, probably due to $\mathrm{CP}$-surfactant $\mathrm{H}$-bond interactions between the $\mathrm{OH}$ groups and the free carboxylic groups present in $\left\{\left[\mathrm{Cu}_{2}\left(\mu_{3} \text {-adeninato }\right)_{2}(\mu \text {-Hadip })_{2}\right]\right\}_{n}$, while the use of cationic surfactants such as $\mathrm{CTAB}$ produces an enhance in the particle size going to the micron scale due to the ionic character of $\left\{\left[\mathrm{Cu}_{2}\left(\mu_{3} \text {-adeninato }\right)_{2}(\mu \text {-Hadip })_{2}\right]\right\}_{n}$.

Finally, the studies carried out in water at different $\mathrm{pH}$ values show that the obtained sub-micron $\mathrm{CP}$ particles are stable over long periods of time and under physiological $\mathrm{pH}$ conditions, without changing their size and morphology. These are the conditions required for further use of this $\mathrm{CP}$ under any potential biological application.

These studies show the variety of synthetic factors, from a bottom-up approach, which can be used to modify the particle size of CPs and how the CP design can produce materials of potential interest for health applications.

Supplementary Materials: The following are available online at www.mdpi.com/2073-4360/9/11/565/s1. Table S1: IR selected data of $\left[\mathrm{Cu}_{2}(\mu-\mathrm{N} 3, \mathrm{~N} 9 \text {-adeninato })_{4}\left(\mathrm{H}_{2} \mathrm{O}\right)_{2}\right] \cdot 5 \mathrm{H}_{2} \mathrm{O}$, Figure S1: FESEM images showing the stability of 1 n following c experimental conditions, versus $\mathrm{pH}$ : (a) $\mathrm{pH}=5$ and (b) $\mathrm{pH}=9$, Figure S2: (a) Sodium dodecylsulfate (SDS), (b) cetyltrimethylammonium bromide (CTAB), and (c) a block copolymer of polyethylene glycol $\left(\mathrm{P}_{123}\right)$ used in this reaction. Table S2: Hydrodynamic radius, $\mathrm{Z}$ potential and $\mathrm{pH}$ values of the different surfactants (SDS, CTAB, and $\mathrm{P}_{123}$ ), in absence of 1n, Figure S3: FESEM images of sub-microparticles obtained heating at $40^{\circ} \mathrm{C}, 5 \mathrm{~min}$ and leaving the solution $20 \mathrm{~h}$ at $25^{\circ} \mathrm{C}$ of compound $1 \mathrm{n}$ (a) and the obtained products in the presence of SDS, at $1 \mathrm{mM}$ (b) $5 \mathrm{mM}$, (c), and $15 \mathrm{mM}$ (d), Figure S4: X-ray powder diffraction patterns of $\left\{\left[\mathrm{Cu}_{2}\left(\mu_{3} \text {-adeninato }\right)_{2}(\mu \text {-Hadip })_{2}\right]\right\}_{\mathrm{n}}$ (1n) (black), 1n with SDS $1 \mathrm{mM}$ (red), 1n with SDS $5 \mathrm{mM}$ (blue) and 1n with SDS $15 \mathrm{mM}$ (green), Figure S5: FESEM images of sub-microparticles obtained heating at $40^{\circ} \mathrm{C}, 5 \mathrm{~min}$ and leaving the solution $20 \mathrm{~h}$ at $25^{\circ} \mathrm{C}$ of compound $1 \mathrm{n}(\mathrm{a})$ and the obtained products in the presence of CTAB, at $1 \mathrm{mM}(\mathrm{b})$, $5 \mathrm{mM}(\mathrm{c})$, and $15 \mathrm{mM}(\mathrm{d})$, Figure S6: X-ray powder diffraction patterns of $\left\{\left[\mathrm{Cu}_{2}\left(\mu_{3} \text {-adeninato }\right)_{2}(\mu \text {-Hadip })_{2}\right]\right\}_{\mathrm{n}}(\mathbf{1 n})$ (black). 1n with CTAB $1 \mathrm{mM}$ (red). 1n with CTAB $5 \mathrm{mM}$ (blue) and 1n with CTAB $15 \mathrm{mM}$ (green), Figure S7: FESEM images of sub-microparticles obtained heating at $40^{\circ} \mathrm{C}, 5 \mathrm{~min}$ and leaving the solution $20 \mathrm{~h}$ at $25^{\circ} \mathrm{C}$ of compound 1n (a) and the obtained products in the presence of $P_{123}$, at $1 \mathrm{mM}$ (b), $5 \mathrm{mM}$ (c), and $15 \mathrm{mM}$ (d), Figure S8: Thermal dependence of $\chi_{m}$ per $\mathrm{Cu}(\mathrm{II})$ dimer for $\left\{\left[\mathrm{Cu}_{2}\left(\mu_{3} \text {-adeninato }\right)_{2}(\mu \text {-Hadip })_{2}\right]\right\}_{n}$ as microcrystals $(\mathbf{1 m})$ and nanocrystals $(\mathbf{1 n})$. The inset shows the thermal variation of the $\chi_{\mathrm{m}} \mathrm{T}$ product. The solid lines are the best fit to the $S=\frac{1}{2}$ dimer model.

Acknowledgments: We thank financial support from the Spanish Ministerio de Economía y Competitividad (MAT2013-46502-C2-2P, MAT2016-75883-C2-2-P), Generalitat Valenciana (Project Prometeo II/2014/076), and also to the scientific computing center (CCC) of the Autonoma University of Madrid for their time. Thanks to Oscar Castillo and Sonia Pérez for their invaluable advice on the synthesis of the studied compound.

Author Contributions: Pilar Amo-Ochoa and Félix Zamora conceived and designed the experiments; Verónica G. Vegas and Marta Villar-Alonso performed the experiments; Pilar Amo-Ochoa and Verónica G. Vegas analyzed the data; Carlos J. Gómez-García performed the magnetic characterization of the samples; and Pilar Amo-Ochoa wrote the paper.

Conflicts of Interest: The authors declare no conflict of interest.

\section{References}

1. Batten, S.R.; Neville, S.M.; Turner, D.R. Coordination Polymers: Design, Analysis and Applications; RSC Publishing: London, UK, 2009; pp. 238-256. 
2. Amo-Ochoa, P.; Alexandre, S.S.; Hribesh, S.; Galindo, M.A.; Castillo, O.; Gómez-García, C.J.; Pike, A.J.; Soler, J.M.; Houlton, A.; Zamora, F. Coordination Chemistry of 6-Thioguanine Derivatives with Cobalt: Toward Formation of Electrical Conductive One-Dimensional Coordination Polymers. Inorg. Chem. 2013, 52, 5290-5299. [CrossRef] [PubMed]

3. Amo-Ochoa, P.; Castillo, O.; Alexandre, S.S.; Welte, L.; de Pablo, P.J.; Rodríguez-Tapiador, M.I.; Gómez-Herrero, J.; Zamora, F. Synthesis of Designed Conductive One-Dimensional Coordination Polymers of $\mathrm{Ni}(\mathrm{II})$ with 6-Mercaptopurine and 6-Thioguanine. Inorg. Chem. 2009, 48, 7931-7936. [CrossRef] [PubMed]

4. Amo-Ochoa, P.; Zamora, F. Coordination polymers with nucleobases: From structural aspects to potential applications. Coord. Chem. Rev. 2014, 276, 34-58. [CrossRef]

5. Zhang, W.X.; Shiga, T.; Miyasaka, H.; Yamashita, M. New Approach for Designing Single-Chain Magnets: Organization of Chains via Hydrogen Bonding between Nucleobases. J. Am. Chem. Soc. 2012, 134, 6908-6911. [CrossRef] [PubMed]

6. Burneo, I.; Stylianou, K.C.; Rodríguez-Hermida, S.; Juanhuix, J.; Fontrodona, X.; Imaz, I.; Maspoch, D. Two New Adenine-Based Co(II) Coordination Polymers: Synthesis, Crystal Structure, Coordination Modes, and Reversible Hydrochromic Behavior. Cryst. Growth Des. 2015, 15, 3182-3189. [CrossRef]

7. Wang, X.H.; Chang, H.; Xie, J.; Zhao, B.; Liu, B.; Xu, S.; Pei, S.; Ren, N.; Huang, L.; Huang, W. Recent developments in lanthanide-based luminescent probes. Coord. Chem. Rev. 2014, 273, $201-212$. [CrossRef]

8. Beobide, G.; Castillo, O.; Cepeda, J.; Luque, A.; Pérez-Yáñez, S.; Román, P.; Thomas-Gipson, J. Metal-carboxylato-nucleobase systems: From supramolecular assemblies to 3D porous materials. Coord. Chem. Rev. 2013, 257, 2716-2736. [CrossRef]

9. Givaja, G.; Amo-Ochoa, P.; Gómez-García, C.J.; Zamora, F. Electrical conductive coordination polymers. Chem. Soc. Rev. 2012, 41, 115-147. [CrossRef] [PubMed]

10. Amo-Ochoa, P.; Castillo, O.; Gómez-García, C.J.; Hassanein, K.; Verma, S.; Kumar, J.; Zamora, F. Semiconductive and Magnetic One-Dimensional Coordination Polymers of $\mathrm{Cu}$ (II) with Modified Nucleobases. Inorg. Chem. 2013, 52, 11428-11437. [CrossRef] [PubMed]

11. Xiao, B.; Byme, P.J.; Wheatley, P.S.; Wragg, D.S.; Zhao, X.; Fletcher, A.J.; Thomas, K.M.; Peters, L.; Evans, J.S.O.; Warren, J.E.; et al. Chemically blockable transformation and ultraselective low-pressure gas adsorption in a non-porous metal organic framework. Nat. Chem. 2009, 1, 289-294. [CrossRef] [PubMed]

12. Zamora, F.; Amo-Ochoa, P.; Sanz Miguel, P.J.; Castillo, O. From metal-nucleobase chemistry towards molecular wires. Inorg. Chim. Acta 2009, 362, 691-706. [CrossRef]

13. Vegas, V.G.; Lorca, R.; Latorre, A.; Hassanein, K.; Gómez-García, C.J.; Castillo, O.; Somoza, A.; Zamora, F.; Amo-Ochoa, P. Copper(II)-Thymine Coordination Polymer Nanoribbons as Potential Oligonucleotide Nanocarriers. Angew. Chem. Int. Ed. 2017, 56, 987-991. [CrossRef] [PubMed]

14. Rodriguez-San-Miguel, D.; Amo-Ochoa, P.; Zamora, Z. MasterChem: Cooking 2D-polymers. Chem. Commun. 2016, 52, 4113-4127. [CrossRef] [PubMed]

15. Neaime, C.; Daiguebonne, C.; Calvez, G.; Freslon, S.; Bernot, K.; Grasset, F.; Cordier, S.; Guillou, O. Nanometrization of Lanthanide-Based Coordination Polymers. Chem. Eur. J. 2015, 21, 17466-17473. [CrossRef] [PubMed]

16. Hermosa, C.; Horrocks, B.R.; Martínez, J.I.; Liscio, F.; Gómez-Herrero, J.; Zamora, F. Mechanical and optical properties of ultralarge flakes of a metal-organic framework with molecular thickness. Chem. Sci. 2015, 6, 2553-2558. [CrossRef]

17. Das, G.; Biswal, B.P.; Kandambeth, S.; Venkatesh, V.; Kaur, G.; Addicoat, M.; Heine, T.; Verma, S.; Banerjee, R. Chemical sensing in two dimensional porous covalent organic nanosheets. Chem. Sci. 2015, 6, 3931-3939. [CrossRef]

18. Liu, K.; Shen, Z.R.; Li, Y.; Han, S.D.; Hu, T.L.; Zhang, D.S.; Bu, X.H.; Ruan, W.J. Solvent induced rapid modulation of micro/nano structures of metal carboxylates coordination polymers: Mechanism and morphology dependent magnetism. Sci. Rep. 2014, 4, 6023. [CrossRef] [PubMed]

19. Derakhshandeh, P.G.; Soleimannejad, J. Sonochemical synthesis of a new nano-sized cerium(III) supramolecular compound; Precursor for nanoceria. Ultrason. Sonochem. 2016, 31, 122-128. [CrossRef] [PubMed] 
20. Huang, C.; Wang, H.; Wang, X.; Gao, K.; Wu, J.; Hou, H.; Fan, Y. Surfactant-Assisted Nanocrystalline Zinc Coordination Polymers: Controlled Particle Sizes and Synergistic Effects in Catalysis. Chem. Eur. J. 2016, 22, 6389-6396. [CrossRef] [PubMed]

21. Baldassarre, F.; Cacciola, M.; Ciccarella, G. A predictive model of iron oxide nanoparticles flocculation tuning Z-potential in aqueous environment for biological application. J. Nanopart. Res. 2015, 17, 377. [CrossRef]

22. Nagapradeep, N.; Venkatesh, V.; Tripathi, S.K.; Verma, S. Guanine-copper coordination polymers: Crystal analysis and application as thin film precursors. Dalton Trans. 2014, 43, 1744-1752. [CrossRef] [PubMed]

23. Nishimura, S.; Ebitani, K. Recent Advances in Heterogeneous Catalysis with Controlled Nanostructured Precious Monometals. Chem CatChem 2016, 8, 2303-2316. [CrossRef]

24. Sharma, B.; Mahata, A.; Mandani, S.; Sarma, T.K.; Pathak, B. Coordination polymer hydrogels through $\mathrm{Ag}(\mathrm{I})$-mediated spontaneous self-assembly of unsubstituted nucleobases and their antimicrobial activity. RSC Adv. 2016, 6, 62968-62973. [CrossRef]

25. Wani, W.A.; Prashar, S.; Shreaz, S.; Gómez-Ruiz, S. Nanostructured materials functionalized with metal complexes: In search of alternatives for administering anticancer metallodrugs. Coord. Chem. Rev. 2016, 312, 67-98. [CrossRef]

26. Pérez-Yáñez, S.; Beobide, G.; Castillo, O.; Cepeda, J.; Luque, A.; Román, P. Directing the Formation of Adenine Coordination Polymers from Tunable Copper(II)/Dicarboxylato/Adenine Paddle-Wheel Building Units. Cryst. Growth Des. 2012, 12, 3324-3334. [CrossRef]

27. Shi, N.E.; Du, W.; Jin, X.; Zhang, Y.; Han, M.; Xu, Z.; Xie, L.; Huang, W. Surfactant Charge Mediated Shape Control of Nano- or Microscaled Coordination Polymers: The Case of Tetrapyridylporphine Based Metal Complex. Cryst. Growth Des. 2014, 14, 1251-1257. [CrossRef]

28. Bain, G.A.; Berry, J.F. Diamagnetic Corrections and Pascal's Constants. J. Chem. Educ. 2008, 85, 532. [CrossRef]

29. Usman, M.; Mendiratta, S.; Lu, K.L. Semiconductor Metal-Organic Frameworks: Future Low-Bandgap Materials. Adv. Mater. 2017, 29, 1605071. [CrossRef] [PubMed]

30. Bunzen, H.; Grzywa, M.; Hambach, M.; Spirkl, S.; Volkmer, D. From Micro to Nano: A Toolbox for Tuning Crystal Size and Morphology of Benzotriazolate-Based Meta-Organic Frameworks. Cryst. Growth Des. 2016, 16, 3190-3197. [CrossRef]

31. Luo, F.; Pan, C.; Cheng, J. Recent Advances in Transition-Metal-Catalyzed Esterification. Synlett 2012, 23, 357-366.

32. Fu, H.; Xiao, D.; Yao, J.; Yang, G. Nanofibers of 1,3-Diphenyl-2-pyrazoline Induced by Cetyltrimethylammonium Bromide Micelles. Angew. Chem. Int. Ed. 2003, 42, 2883-2886. [CrossRef] [PubMed]

33. Boonmak, J.; Nakano, M.; Chaichit, N.; Pakawatchai, C.; Youngme, S. Spin Canting and Metamagnetism in 2D and 3D Cobalt(II) Coordination Networks with Alternating Double End-On and Double End-to-End Azido Bridges. Inorg. Chem. 2011, 50, 7324-7333. [CrossRef] [PubMed]

34. Kan, J.; Chen, Y.; Gao, J.; Wan, L.; Lei, T.; Ma, P.; Jiang, J. Synthesis, self-assembly, and semiconducting properties of phenanthroline-fused phthalocyanine derivatives. J. Mater. Chem. 2012, 22, 15695-15701. [CrossRef]

(C) 2017 by the authors. Licensee MDPI, Basel, Switzerland. This article is an open access article distributed under the terms and conditions of the Creative Commons Attribution (CC BY) license (http://creativecommons.org/licenses/by/4.0/). 